Supplement of Biogeosciences, 14, 2571-2596, 2017

http://www.biogeosciences.net/14/2571/2017/

doi:10.5194/bg-14-2571-2017-supplement

(C) Author(s) 2017. CC Attribution 3.0 License.

(c) (i)

Supplement of

\title{
Modelling Holocene peatland dynamics with an individual-based dynamic vegetation model
}

Nitin Chaudhary et al.

Correspondence to: Nitin Chaudhary (nitin.chj@gmail.com)

The copyright of individual parts of the supplement might differ from the CC-BY 3.0 licence. 
Table S1. Comparison of functionality and scope of a representative set of current peatland models.

\begin{tabular}{|c|c|c|c|c|c|c|c|c|c|}
\hline Schemes & Peatland & Permafrost & DGVM & $\begin{array}{c}\text { Multiple } \\
\text { annual peat } \\
\text { layers }\end{array}$ & $\begin{array}{c}\text { Spatial } \\
\text { heterogeneity }\end{array}$ & Methane & $\begin{array}{l}\text { Coupled } \\
\text { to ESM }\end{array}$ & $\begin{array}{l}\text { Single } \\
\text { site }\end{array}$ & $\begin{array}{c}\text { Global/Regi } \\
\text { onal } \\
\text { application }\end{array}$ \\
\hline This study & $\checkmark$ & 2 & $\checkmark$ & $\checkmark$ & $\checkmark$ & $x$ & $x$ & 2 & $\checkmark$ \\
\hline $\begin{array}{l}\text { Wu et al. } \\
(2016)\end{array}$ & $\checkmark$ & $x$ & $x$ & $x$ & $x$ & $x$ & $\checkmark$ & $\checkmark$ & $\checkmark$ \\
\hline $\begin{array}{l}\text { Alexandrov } \\
\text { et al. }(2016)\end{array}$ & $\checkmark$ & $x$ & $x$ & $x$ & $x$ & $x$ & $x$ & $x$ & $\checkmark$ \\
\hline $\begin{array}{l}\text { Tang et al. } \\
\text { (2015b) }\end{array}$ & $\checkmark$ & $\checkmark$ & $\checkmark$ & $x$ & $x$ & $\checkmark$ & $x$ & $\checkmark$ & $\checkmark$ \\
\hline $\begin{array}{l}\text { Stocker et al. } \\
(2014)\end{array}$ & $\checkmark$ & $x$ & $\checkmark$ & $x$ & $x$ & $x$ & $x$ & $x$ & $\checkmark$ \\
\hline $\begin{array}{l}\text { Morris et al. } \\
(2012)\end{array}$ & $\checkmark$ & $x$ & $x$ & $x$ & $\checkmark$ & $x$ & $x$ & $\checkmark$ & $x$ \\
\hline $\begin{array}{l}\text { Schuldt et al. } \\
(2013)\end{array}$ & $\checkmark$ & $x$ & $\checkmark$ & $x$ & $x$ & $\checkmark$ & $\checkmark$ & $\checkmark$ & $\checkmark$ \\
\hline $\begin{array}{l}\text { Kleinen et } \\
\text { al. (2012) }\end{array}$ & $\checkmark$ & $x$ & $\checkmark$ & $x$ & $x$ & $x$ & $x$ & $\checkmark$ & $\checkmark$ \\
\hline $\begin{array}{l}\text { Heinemeyer } \\
\text { et al. }(2010)\end{array}$ & $\checkmark$ & $x$ & $x$ & $\checkmark$ & $x$ & $x$ & $x$ & $\checkmark$ & $x$ \\
\hline $\begin{array}{l}\text { Frolking et } \\
\text { al. }(2010)\end{array}$ & $\checkmark$ & $x$ & $x$ & $\checkmark$ & $x$ & $x$ & $x$ & $\checkmark$ & $x$ \\
\hline $\begin{array}{l}\text { Wania et al. } \\
(2009 a)\end{array}$ & $\checkmark$ & $\checkmark$ & $\checkmark$ & $x$ & $x$ & $\checkmark$ & $x$ & $x$ & $\checkmark$ \\
\hline $\begin{array}{l}\text { Ise et al. } \\
(2008)\end{array}$ & $\checkmark$ & $x$ & $x$ & $x$ & $x$ & $x$ & $x$ & $\checkmark$ & $x$ \\
\hline $\begin{array}{l}\text { Bauer } \\
(2004)\end{array}$ & $\checkmark$ & $x$ & $x$ & $\checkmark$ & $x$ & $x$ & $x$ & $\checkmark$ & $x$ \\
\hline $\begin{array}{l}\text { Hilbert et al. } \\
(2000)\end{array}$ & $\checkmark$ & $x$ & $x$ & $x$ & $x$ & $x$ & $x$ & $\checkmark$ & $x$ \\
\hline $\begin{array}{l}\text { Clymo } \\
(1984)\end{array}$ & $\checkmark$ & $x$ & $x$ & $x$ & $x$ & $x$ & $x$ & $\checkmark$ & $x$ \\
\hline $\begin{array}{l}\text { Ingram } \\
(1982)\end{array}$ & $\checkmark$ & $x$ & $x$ & $x$ & $x$ & $x$ & $x$ & $\checkmark$ & $x$ \\
\hline
\end{tabular}

